\title{
25 Years authentication of wine with stable isotope analysis in the European Union - Review and outlook
}

\author{
Norbert Christoph ${ }^{1}$, Armin Hermann ${ }^{2}$, and Helmut Wachter ${ }^{1}$ \\ ${ }^{1}$ Bavarian Health and Food Safety Authority (LGL), 97082 Würzburg, Germany \\ ${ }^{2}$ Landesuntersuchungsamt Rheinland-Pfalz, Institut für Lebensmittelchemie und Arzneimittelprüfung, 55129 Mainz, \\ Germany
}

\begin{abstract}
The implementation of stable isotope applications in official food analyses began in 1990. At that time the first method to detect sucrose from sugar beet or sugar cane in wine by Deuterium-Nuclear Magnetic Resonance ( $\left.{ }^{2} \mathrm{H}-\mathrm{NMR}\right)$ of ethanol, also known as SNIF-NMR ${ }^{\circledR}$-Method became adopted officially by the European Commission. This was a milestone for an improved authentication of wines and other food stuffs. In connection with methods using Isotope Ratio Mass Spectrometry (IRMS), stable isotope ratio analysis is one of the most powerful analytical tools for authentication of wine. The fundamentals of biotic and abiotic stable isotope fractionation and the analytical methods which are used in authentication of wine are summarized. Principles of authentication of some wine constituents like sugar, ethanol, organic acids, glycerol, and carbon dioxide as well as proof of geographic origin are reviewed. By selected example of anonymized cases, proof of adulterations (e.g. chaptalization, addition of water or mislabeling) using monovariate, bivariate, and multivariate data evaluations are discussed. It is shown that for this purpose databanks are generally indispensable. In their absence cut-off values, derived from long-term observations help to detect clear adulterations.
\end{abstract}

\section{Introduction}

Authentication of wine is the analytical process by which a wine is verified as being in compliance with legal regulations. Authentication is not only imperative for consumer protection with respect to an increased and globalized wine market. There is also a high interest of wine producers and traders to offer wines of high quality and reliable authenticity. Finally it is a political and economic objective of each wine producing country to market internationally well reputed wines. Although quality awareness of wine producers is on a rather high level all over the world, there have been and still are incentives to produce wine by illegal practices. Furthermore, during the last decades, adulterations became more and more sophisticated, thus the development of even more powerful analytical methods for wine authentication has been an important concern in wine analytics. The recognition of stable isotopes as genuine markers of food was a milestone of improved food authentication. Stable Isotope Ratio Analysis (SIRA) of the bio-elements ${ }^{2} \mathrm{H},{ }^{13} \mathrm{C}$, and ${ }^{18} \mathrm{O}$ in biomolecules of food started already in early Seventies [1,2]. One important breakthrough in authentication was the development of an analytical method based on Deuterium-Nuclear Magnetic Resonance ( $\left.{ }^{2} \mathrm{H}-\mathrm{NMR}\right)$ also known as SNIF-NMR ${ }^{\circledR}$ Method [3]. This method, invented by Prof. G.J. Martin, Nantes, was first applied to detect chaptalization of wines. In 1990, 25 years ago, this method was adopted by the European Commission (EC) as the first official analytical method based on the determination of stable isotopes [4]. In subsequent years, further applications with SIRA for wine analysis became adopted by the EC. In the following the fundamentals of authentication of wine with SIRA and the wide experiences gained throughout 25 years are reviewed. Possibilities of authentication and proof of adulterations are presented by example of selected and anonymized cases. Finally some prospects of future use of stable isotope analysis are discussed.

\section{Stable isotope fractionation effects}

Authentication of wine and other food products by SIRA is based on the inter- and intra-molecular non-statistical distribution of the stable isotopes of the bio-elements carbon $\left({ }^{13} \mathrm{C} /{ }^{12} \mathrm{C}\right)$, hydrogen $\left({ }^{2} \mathrm{H} /{ }^{1} \mathrm{H}\right)$, and oxygen $\left({ }^{18} \mathrm{O} /{ }^{16} \mathrm{O}\right)$. The distribution of isotopes in biomolecules of sugar, organic acids, water, or fermented components like ethanol and glycerol is controlled by so-called biotic and abiotic fractionation processes. The results of these processes are stable isotope patterns which are characteristic for a specific year of vintage or geographical origin of a grape or a wine. Only by knowledge of the mechanisms responsible for such patterns, an expert interpretation of stable isotope data with respect to authenticity or adulteration is feasible. Figure 1 shows the main general parameters which are influencing biotic and abiotic effects of fractionation of stable isotopes in grapes.

\subsection{Abiotic fractionation}

Abiotic processes of fractionation are mainly induced by thermodynamic and/or kinetic isotope effects. Important fractionation processes are water evaporation/condensation and the ${ }^{18} \mathrm{O}$-isotope equilibration between water and 


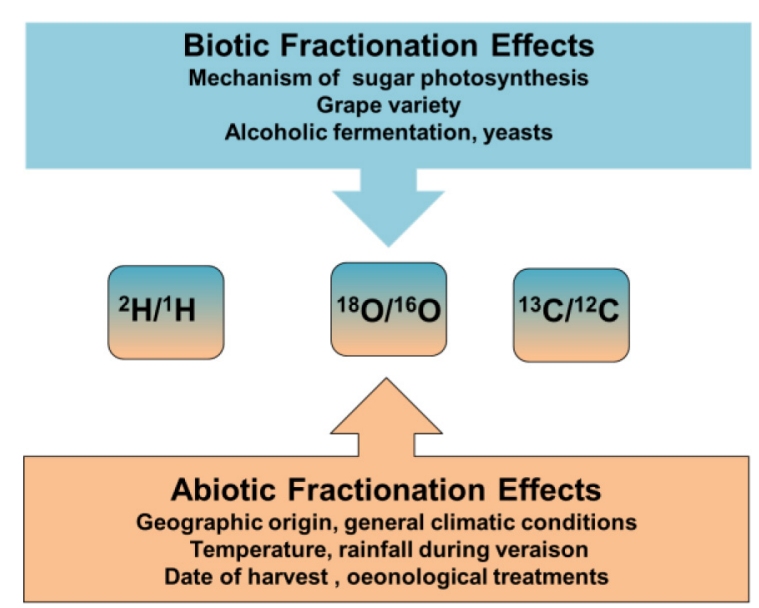

Figure 1. Biotic and abiotic fractionation effects on stable isotopes of grape and wine constituents.

$\mathrm{CO}_{2}$. The following general rules have to be taken into consideration with regard to enrichment or depletion of the heavier stable isotopes ${ }^{2} \mathrm{H}$ and ${ }^{18} \mathrm{O}$ in precipitation water [5-7]:

- Latitude effect: depletion with increasing latitude because of the increasing degree of "rain-out".

- Continental effect: depletion from coast to inland.

- Temperature effect: enrichment with increase of average temperature

- Amount effect: Depletion the greater the amount of rainfall.

- Altitude effect: depletion with increasing altitude.

Further abiotic fractionation process takes place in the grape water and the vine leafs. Evapotranspiration through the stomata or through the grape skin enriches both ${ }^{18} \mathrm{O}$ and ${ }^{2} \mathrm{H}$ in grape or leaf water. The extent of the enrichment depends on factors like microclimatic conditions (e.g. relative humidity and its isotope signature) but also physiological and viticultural parameters like and sun exposure of the vineyard, water sustenance of soil, irrigation, maturation period, and date of harvest.

\subsection{Biotic fractionation}

The best known and important biotic fractionation effect is the carbon-isotope discrimination, which is a result of the different $\mathrm{CO}_{2}$-fixation processes by photosynthesis in the so-called $\mathrm{C}_{3}-$ and $\mathrm{C}_{4}$-plants. $\mathrm{C}_{3}$-plants, the name is derived from the number of carbon atoms of phosphoglyceric acid, which is the first photosynthetic product, have a large isotope effect on the ribulose-bisphosphate-carboxylase reaction, with the result of a strong depletion of the ${ }^{13} \mathrm{C}$-isotopes [1,7]. $\mathrm{C}_{3}$-plants represent the most abundant group of plants and comprise almost all fruits growing in Europe including the grape-vine, grain and sugar beet. The term $\mathrm{C}_{4}$-plants is derived from four $\mathrm{C}$-atoms of the oxalacetate, the photosynthetic product of the phosphoenolpyruvate-carboxylase reaction. Due to a smaller isotope effect more ${ }^{13} \mathrm{C}$ is less depleted than in $\mathrm{C}_{3}$-plants. The best known $\mathrm{C}_{4}$ plants are sugar cane, corn, or millet. In parallel with the different $\mathrm{CO}_{2}$-fixation process there is also a corresponding isotope effect for the ${ }^{2} \mathrm{H}$-isotope with depletion for $\mathrm{C}_{3}$-plants and enrichment for the sugars in $\mathrm{C}_{4}$-plants.

\subsubsection{Site specific natural isotope fractionation}

The site specific natural isotope fractionation of the ${ }^{2} \mathrm{H}$-isotope (Deuterium) detected by Martin [3,8] and basis for the so-called SNIF-NMR ${ }^{\circledR}$ Method to detect chaptalization with sucrose from sugar beet, is based on the fact that deuterium from the sugar- and water-molecule is transferred differently during alcoholic fermentation into the methyl- and the methylene-position of the ethanol molecule. Approximately $85 \%$ of deuterium in the sugar molecule is transferred into the methyl-group of ethanol and about $75 \%$ of the deuterium of grape water into the methylene-group. Thus the resulting isotope ratio of the methyl group which is defined as $(\mathrm{D} / \mathrm{H})_{\mathrm{I}}$ represents the botanical origin of the fermented sugar whereas that of the methylene group $(\mathrm{D} / \mathrm{H})_{\mathrm{II}}$ is typical for the deuterium content of the grape-water and reflects the climatic conditions related to the geographical origin and the year of vintage.

\section{Methods of stable isotope ratio analysis}

Table 1 shows the validated and officially approved analytical methods for wine using IRMS and ${ }^{2} \mathrm{H}-\mathrm{NMR}$ for the determination of stable isotope ratios in wine constituents. The methods are published in the "Compendium of International Methods of Wine and Must Analysis" of the International Organization of Vine and Wine (OIV) [9].

The variations in the natural abundance of stable isotopes are commonly expressed as deviations relative to international standards (Table 1). These deviations are normally in the order of parts per thousand (\%o) only. The symbol for the isotopic results, when expressed relative to a standard is delta $(\delta)$, e.g. $\delta^{13} \mathrm{C}$. In case of the ${ }^{2} \mathrm{H}-\mathrm{NMR}$ method the $\mathrm{D} / \mathrm{H}$-values are expressed in ppm (i.e. as a fraction). ${ }^{2} \mathrm{H}-\mathrm{NMR}$ analysis of wine sugar or ethanol is a rather time-consuming method which is performed only in a few official and commercial laboratories. However it is still the only method to prove chaptalization or sweetening of a wine with beet sugar. IRMS analysis is used more widely; it can be hyphenated with various analysers, interfaces, and couplings like GC, LC, HPLC, or Gas Bench

Table 1. Analytical methods approved for the determination of stable isotope ratios in wine constituents by OIV [9].

\begin{tabular}{|c|c|c|}
\hline $\begin{array}{l}\text { Analytical } \\
\text { Method }\end{array}$ & $\begin{array}{c}\text { Molecule } \\
\text { (OIV Method) }\end{array}$ & $\begin{array}{l}\text { Isotope } \\
\text { ratio }\end{array}$ \\
\hline $\begin{array}{c}{ }^{2} \mathrm{H}-\mathrm{NMR} \\
\left(\mathrm{SNIF}^{\circledR}-\mathrm{NMR}\right)\end{array}$ & $\begin{array}{c}\text { Sugar, ethanol } \\
(O I V-M A-A S 311-05)\end{array}$ & $\begin{array}{l}(\mathrm{D} / \mathrm{H})_{\mathrm{I}} \mathrm{ppm} \\
(\mathrm{D} / \mathrm{H})_{\mathrm{II}} \mathrm{ppm}\end{array}$ \\
\hline $\begin{array}{l}{ }^{13} \mathrm{C} /{ }^{12} \mathrm{C} \\
\text { IRMS }\end{array}$ & $\begin{array}{c}\text { Sugar, ethanol, } \\
\text { (OIV-MA-AS312-06) } \\
\text { Glycerol } \\
\text { (OIV-MA-AS312-07) } \\
\text { Carbon dioxide } \\
\text { (OIV-MA-AS314-03) }\end{array}$ & $\begin{array}{c}\delta^{13} \mathrm{C} \\
\% o \mathrm{~V}-\mathrm{PDB}\end{array}$ \\
\hline $\begin{array}{l}{ }^{18} \mathrm{O} /{ }^{16} \mathrm{O} \\
\text { IRMS }\end{array}$ & $\begin{array}{c}\text { Water } \\
(O I V-M A-A S 2-12)\end{array}$ & $\begin{array}{c}\delta^{18} \mathrm{O} \\
\% \circ \mathrm{V}-\mathrm{SMOW}\end{array}$ \\
\hline
\end{tabular}

D, Deuterium $\left({ }^{2} \mathrm{H}\right)$; V-SMOW: Vienna Standard Mean Ocean Water, $\delta^{18} \mathrm{O}=0 \%$ V-SMOW; V-PDB: Vienna Pee Dee Belemnite, $\delta^{13} \mathrm{C}=0 \%$ V-PDB. 
and enables a faster and even more sensitive analysis of different isotope ratios. Furthermore it is virtually applicable to all wine constituents, even aroma compounds.

One important prerequisite for the use of SIRA to a profound assessment of wine authenticity are validated analytical methods with defined quality parameters. For this purpose, Proficiency Testing Schemes (PTS) were implemented by Eurofins Scientific in 1994 and have been continued within the framework of a European research program called "Food analysis using Isotopic Techniques" (FIT). Since 1999, this PTS, now called FIT-PTS is recognized by accreditation bodies as a valid proficiency testing scheme and actually includes more than 50 laboratories worldwide [10].

\section{Databanks - indispensable tools for wine authentication}

Authenticity testing of wines by SIRA rely to a large extend on analytical data of a set of authentic reference samples. The selection of suitable reference samples is also crucial. In an optimum situation, the reference samples coincide in terms of origin, and (date of) vintage, with the wine to be analysed.

\subsection{EU Wine Databank}

In 1991, a decree for the establishment of an official wine databank (EU-WineDB) at the Joint Research Centre (JRC) in Ispra/Italy was launched by the European Commission (EC). The EU-WineDB actually contains the isotopic results of authentic and representative samples from EU Member States (MS) with wine-growing regions since 1992.

Corresponding to the actual regulation for the EU-WineDB [11] more than 1400 samples of grapes (15 kg each) are taken by official controllers in the winegrowing regions of $17 \mathrm{MS}$ of the EU annually. The number of samples to be taken varies from 400 for Italy or France down to 4 samples for United Kingdom or Luxemburg only. $15 \mathrm{~kg}$ of grapes are picked by authorized officers and fermented by micro-vinification. SIRA is performed in official institutes of most of the MS. The results are sent to the JRC for entering the EU-WineDB. The main purpose of EU-WineDB is to use the data for official wine control whereas a MS has access to its own data only. If a wine, imported from MS1 to MS2 shows a suspicious stable isotopic result, suitable data from EU-WineDB of MS1 can be requested by MS2 to use them for authenticity assessment and as basis for an expertise in official wine control [11].

\subsection{Third Country Databank}

Since the official wine control bodies in EU may also be confronted with fraudulently produced or mislabeled wines from a non-EU country ("Third country"), a socalled "Third-Country Databank" was established in Germany in 1994. The databank contains data of otherwise unsuspicious commercial wines from virtually all places in the world. At the moment, data from wines of 26 nations are available. Those wines were taken from the German retail market or by customs authorities. This databank is an important tool for a first check of authenticity for a wine from a third country by official wine control.

\subsection{Further sources of stable isotope data}

Stable isotope data are not only collected by official laboratories of wine control but also by research institutes, commercial laboratories, and laboratories responsible for quality control in wine industry. In the last 25 years, numerous scientific studies have been published on stable isotope data of wines with respect to various phenomena. This information represents a comprehensive knowledge base. Besides data sets in data banks this theoretical framework can be used additionally for the interpretation of stable isotope pattern of wines.

\section{Review on issues of authentication}

The issues and procedures of authentication of a wine using stable isotope data are very complex.

This is due to the diversity of wines with various designations, oenological practices, legal regulations as well as different possibilities of adulterations. Table 2 summarizes the most relevant issues of authentication of a wine with SIRA and the corresponding stable isotope ratios, which should be available for the issue in question. In the following some important details and aspects concerning single challenges of wine authentication and proof of adulterations are reviewed and discussed.

\subsection{Authentication of wine ethanol and sugar}

In the EU chaptalization with sucrose is permitted in the wine-growing zones A and B only. Increasing the natural amount of alcohol (sugar) of a grape must by maximum of $3 \%$ vol up to a limit of $15 \%$ vol meets legal constraints [12]. Exceptional permits of chaptalization up to more than $3 \%$ vol for compensation of ripening deficits caused by adverse meteorological situations have to be considered.

Figure 2 shows the principle of the proof of chaptalization, which can also be used for a proof of sweetening with non-grape sugars. The $(\mathrm{D} / \mathrm{H})_{\mathrm{I}}$-ratio of ethanol from beet or cane sugar is significantly different from that of wine. For wines of the EC the $(\mathrm{D} / \mathrm{H})_{\mathrm{I}}$-parameter ranges approximately between 98 to $104 \mathrm{ppm}$. By capitalizing a grape must, the natural $(\mathrm{D} / \mathrm{H})$-ratio decreases as the amount of beet-sugar increases. In the same way, however more surging, the $(\mathrm{D} / \mathrm{H})_{\mathrm{I}}$-ratio increases by use of cane sugar. Mixtures of beet and cane sugar may compensate each other but by additional ${ }^{13} \mathrm{C}$-IRMS analysis the cane sugar component will be detected nevertheless. Therefore it is always advisable to determine both the $(\mathrm{D} / \mathrm{H})_{\mathrm{I}}-$ and $\delta^{13} \mathrm{C}$ value of wine ethanol [13,14].

Internal standardization (correlation) of data by analysis of stable isotope ratios of different wine constituents may help to reduce the uncertainty-limit to detect possible adulterations such as addition of $\mathrm{C}_{4}$-plant sugar. High correlations were found between the $\delta^{13} \mathrm{C}$-values of sugars from heterosides (glycosides) and total sugar of a wine or grape must as well as between the $\delta^{13} \mathrm{C}$-values of amino acids and alcohol [15]. 
Table 2. Stable isotope ratios used for different issues of wine authentication.

\begin{tabular}{|c|c|}
\hline $\begin{array}{c}\text { Issue of } \\
\text { Wine Authentication } \\
\text { (Proof of adulterations) }\end{array}$ & Stable isotope ratios \\
\hline $\begin{array}{l}\text { Ethanol } \\
\text { (chaptalization) }\end{array}$ & $\begin{array}{l}(\mathrm{D} / \mathrm{H})_{\mathrm{I}},(\mathrm{D} / \mathrm{H})_{\mathrm{II}} \mathrm{R} \text {-value } \\
\delta^{13} \mathrm{C} \text { of sugars/ethanol }\end{array}$ \\
\hline $\begin{array}{l}\text { Sugars } \\
\text { (beet, cane, mixtures) }\end{array}$ & $\begin{array}{l}(\mathrm{D} / \mathrm{H})_{\mathrm{I}},(\mathrm{D} / \mathrm{H})_{\mathrm{II}}, \mathrm{R} \text {-value, } \\
\delta^{13} \mathrm{C} \text { sugars/ethanol }\end{array}$ \\
\hline $\begin{array}{l}\text { Water } \\
\text { (water addition) }\end{array}$ & $\begin{array}{l}\delta^{18} \mathrm{O} \text { water } \\
(\mathrm{D} / \mathrm{H})_{\mathrm{II}} \text { ethanol }\end{array}$ \\
\hline $\begin{array}{l}\text { Glycerol } \\
\text { (synthetic, animal) }\end{array}$ & $\delta^{13} \mathrm{C}$ glycerol \\
\hline $\begin{array}{l}\text { Carbon dioxide } \\
\text { (synthetic, fossil) }\end{array}$ & $\delta^{13} \mathrm{C}$ carbon dioxide \\
\hline $\begin{array}{l}\text { Tartaric acid } \\
\text { Synthetic }\end{array}$ & $\delta^{13} \mathrm{C}$ tartaric acid \\
\hline $\begin{array}{l}\text { Geografic origin } \\
\text { mislabelling }\end{array}$ & $\begin{array}{l}(\mathrm{D} / \mathrm{H})_{\mathrm{I}},(\mathrm{D} / \mathrm{H})_{\mathrm{II}} \\
\delta^{13} \mathrm{C} \text { ethanol, } \delta^{18} \mathrm{O} \text { water }\end{array}$ \\
\hline $\begin{array}{l}\text { Year of vintage } \\
\text { Period of vintage }\end{array}$ & $\begin{array}{l}(\mathrm{D} / \mathrm{H})_{\mathrm{I}},(\mathrm{D} / \mathrm{H})_{\mathrm{II}}, \delta^{13} \mathrm{C} \text { ethanol, } \\
\delta^{18} \mathrm{O} \text { water }\end{array}$ \\
\hline
\end{tabular}

\subsection{Authentication of wine water}

The ${ }^{18} \mathrm{O} /{ }^{16} \mathrm{O}$-ratio $\left(\delta^{18} \mathrm{O}\right.$-value) is generally appreciated as an authenticity parameter of wine since the Seventies $[2,7,13-18]$. It is known that after veraison the heavier ${ }^{18} \mathrm{O}$ isotope is enriched in grape water up to values higher than $+10 \%$ V-SMOW. The level of enrichment may differ between years, but also between regions and is mainly influenced by isotopic content of air humidity and by climatic conditions of the particular geographic site (cf. 2.1). In any case the $\delta^{18} \mathrm{O}$ value of wine water can be used as a parameter to prove water addition or as a marker for the geographic origin and year of vintage. However data from an adequate number of representative reference

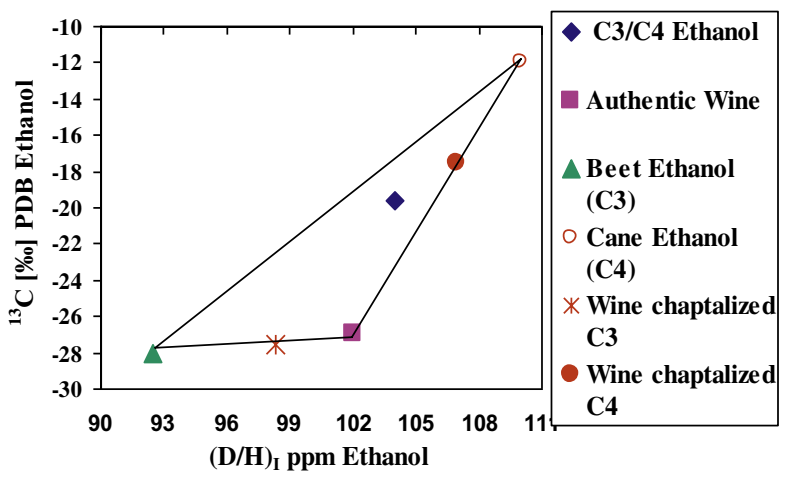

Figure 2. Principle of proof of chaptalization or sweetening of a wine with beet-, cane-sugar, and their mixtures using SNIF$\mathrm{NMR}^{\circledR}$ and ${ }^{13} \mathrm{C}$-IRMS analysis of ethanol [14].

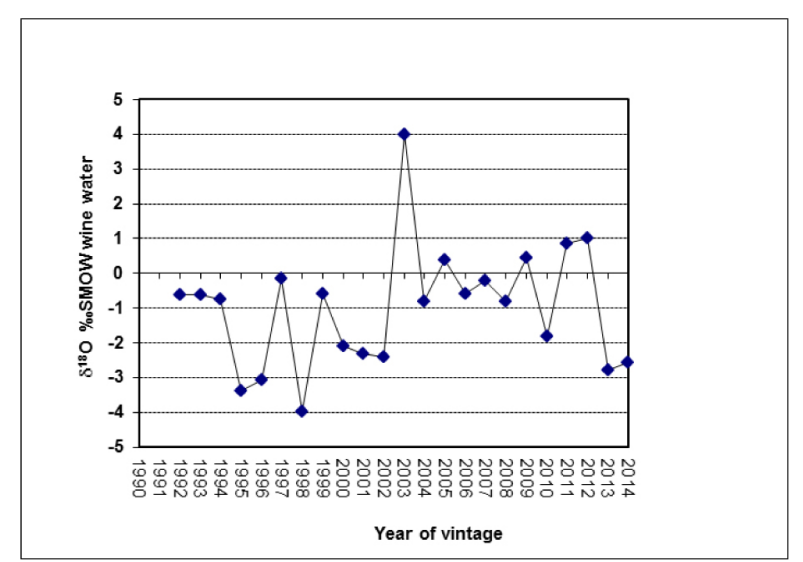

Figure 3. Variation of the mean $\delta^{18} \mathrm{O}$-values of wine water, EU-WineDB, Franconia (Germany) vintage 1991 to 2014.

samples, e.g. from a databank must be available. Vintage effects like extraordinary meteorological conditions after veraison may help to understand particular deviations from expected $\delta^{18} \mathrm{O}$-values from a particular geographic origin or from sites which are not covered by data from a databank [2,13-18]. In such cases tools like online weather archives should be considered. Figure 3 shows the variation of the mean $\delta^{18} \mathrm{O}$-values of wine water of 15 EU-WineDB samples, taken each year in Franconia/ Germany since 1991.

The mean $\delta^{18} \mathrm{O}$-value of wine water calculated for a period of 22 years is $-1 \%$ o V-SMOW with a standard deviation of $1.8 \%$. The plot of the annual variation shows one extreme maximum with a $\delta^{18} \mathrm{O}$-value in 2003 of $+4 \%$ $\mathrm{V}-\mathrm{SMOW}$. The high $\delta^{18} \mathrm{O}$-value rather typical for Southern European countries with a warm climate was caused by a long lasting warm and dry period after veraison. This implicated a very early harvest in late August, whereas the usual period of harvest in Franconia is between September and October. In contrast the minimum $\delta^{18} \mathrm{O}$-values in 1995, 1998, 2013, and 2014 were caused by higher precipitation and cool climate conditions before harvest. The standard deviation of the $\mathrm{d}^{13} \mathrm{C}$-value of ethanol calculated for 22 years is $1.0 \%$ (mean value of 22 years $-27.9 \%$ o $\mathrm{V}-\mathrm{PDB}$ ) and that of the (DH) equals $1.0 \mathrm{ppm}$ (mean value of 22 years $100.7 \mathrm{ppm})$. The $(\mathrm{DH})_{\mathrm{II}}$-value of ethanol (mean value of 22 years $125 \mathrm{ppm}$ ), which is more correlating with the $\delta^{18} \mathrm{O}$-value of water, indicates a corresponding higher standard deviation of $1.4 \mathrm{ppm}$.

Finally the relation between date of grape picking and $\delta^{18} \mathrm{O}$-value in wine water needs to be considered, at least in some years. These irregular changes between and within years are due to different climatic conditions during grape maturation. Figure 4 shows a general trend towards a depletion of ${ }^{18} \mathrm{O}$ in grape- or wine-water. In 2010 to 2014 commercially produced grape musts from containers $>10,0001$ have been analyzed. The data show that for some vintages (e.g. 2012), where the transient depletion of ${ }^{18} \mathrm{O}$ is strongly pronounced, it would be inadequate to neglect the date of harvest in wine authentication, while for other (e.g. Germany 2010) the date of harvest has no effect at all. 


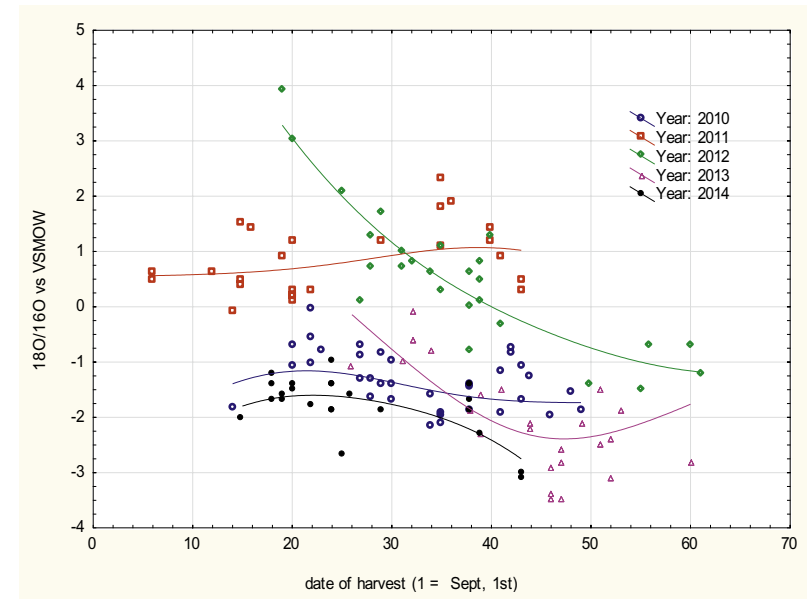

Figure 4. Variation of $\delta^{18} \mathrm{O}$-values in water of grape or wine samples (containers $>10.000 \mathrm{~L}$ ) taken during 60 days period of harvesting in selected German wine-growing regions 2010-2014.

\subsubsection{Authentication of water via wine ethanol}

Recently the combined analysis of the ${ }^{18} \mathrm{O} /{ }^{16} \mathrm{O}$ stable isotope ratio (expressed as $\delta^{18} \mathrm{O}$ ) of ethanol and water is used to improve detection of a water addition to wine. Ethanol recovered by distillation for the SNIF-NMR ${ }^{\circledR}$ analysis, is dried by storing the distillate for at least $24 \mathrm{~h}$ on a molecular sieve. The ${ }^{18} \mathrm{O} /{ }^{16} \mathrm{O}$ ratio is measured using IRMS with a pyrolysis system [19]. In a non-adulterated wine the $\delta^{18} \mathrm{O}$ of ethanol is linearly related to the $\delta^{18} \mathrm{O}$ of the fermentation water. Deviation from the expected relation can indicate a dilution. In principle, this method works without a comparison with a set of authentic reference samples [20,21].

\subsection{Authentication of organic acids}

Within the EC the wine production industry is often faced with the problem of origin control of tartaric acid. This has led to the decision that only L-tartaric acid extracted from grapes as a lawful mean for acidification. IRMS analysis of the isotope ratios of ${ }^{18} \mathrm{O}$ and ${ }^{13} \mathrm{C}$ is a suitable technique for distinguishing natural and synthetic L-tartaric acid. Even the geographical origin and year of production of the natural tartaric acid can be identified [22].

\subsection{Authentication of glycerol}

Authentication of glycerol is imperative, since adulterations by addition of exogenous glycerol were frequently observed in the past. Proof of glycerol addition is possible by identification of by-products of industrial produced glycerol using gas chromatography/mass spectrometry [9, 22]. However, for purified glycerol, the IRMS analysis of ${ }^{13} \mathrm{C} /{ }^{12} \mathrm{C}$ - and ${ }^{18} \mathrm{O} /{ }^{16} \mathrm{O}$-ratio of glycerol [23] or even ${ }^{2} \mathrm{H}-\mathrm{NMR}$ for determination of ${ }^{2} \mathrm{H}$ site-specific ratios in glycerol molecule [24], are options to prove such a fraud.

\subsection{Authentication of carbon dioxide}

Carbon dioxide $\left(\mathrm{CO}_{2}\right)$ in sparkling wines must originate from the second fermentation only. However, $\mathrm{CO}_{2}$ is also used in food industry, where it is obtained from combustion of fossil fuels or from thermal treatment of inorganic carbonates. Consequently, the ${ }^{13} \mathrm{C}$ content of this "industrial"- $\mathrm{CO}_{2}$ is quite different from "fermentation"$\mathrm{CO}_{2}$. Studies performed on $\mathrm{CO}_{2}$ from sparkling wines have shown that the $\mathrm{CO}_{2}$ obtained by fermentation of sugar from $\mathrm{C}_{3}$ plants has $\delta^{13} \mathrm{C}$-values in the range of $-17 \%$ o to $-26 \%$ PDB, whereas $\mathrm{CO}_{2}$ obtained by fermentation of sugar from $\mathrm{C}_{4}$-plants has a $\delta^{13} \mathrm{C}$ in the range of $-7 \%$ o to $-10 \%$ o. Gasified wines, using "industrial"- $\mathrm{CO}_{2}$ have $\delta^{13} \mathrm{C}$ values below $-29 \%$ or above $-10 \%$, depending on the carbon dioxide source. Therefore, the measurement of the stable carbon isotope ratio $\left({ }^{13} \mathrm{C} /{ }^{12} \mathrm{C}\right)$ of $\mathrm{CO}_{2}$ from sparkling wines is a method for tracing the origin of $\mathrm{CO}_{2}$ in sparkling wines [9,26-28].

\subsection{Authentication of geographic origin}

Many studies have been published on the general or specific influence of geographic origin on stable isotope ratios in wine constituents [13-18,29-35].

As a general rule it can be stated that stable isotopes of sugar and water are the more enriched the warmer and dryer is the climate.

Table 4 shows the significant differences of the variation of stable isotope ratios in wine constituents from Central and Southern Europe. Generally wines from southern wine-growing regions in the EU like Italy, Spain, Greece, or Southern France show significantly higher isotope ratios than in Austria, Germany, Czech Republic, or Northern France. Higher annual variations of isotope ratios in wines from Central Europa but also countries with northern and southern wine growing regions like Italy and France are caused by a higher variation of the meteorological and microclimatic conditions.

Camin and Co-workers [35] showed the relationship between $(\mathrm{D} / \mathrm{H})_{\mathrm{I}},(\mathrm{D} / \mathrm{H})_{\mathrm{II}}$, and $\delta^{13} \mathrm{C}$ of ethanol, $\delta^{18} \mathrm{O}$ of wine

Table 3. Typical variation of stable isotope ratios of wine water and ethanol in wines from some selected countries or continents.

\begin{tabular}{|l|c|c|c|}
\hline \multicolumn{1}{|c|}{ Country } & $\begin{array}{c}\mathbf{d}^{\mathbf{1 8}} \mathbf{O} \\
\text { \%o V-SMOW } \\
\text { wine water }\end{array}$ & $\begin{array}{c}(\mathbf{D} / \mathbf{H})_{\mathbf{I}} \\
\mathbf{p p m} \\
\text { ethanol }\end{array}$ & $\begin{array}{c}\mathbf{d}^{\mathbf{1 3}} \mathbf{C} \\
\mathbf{\%} \mathbf{\text { V-PDB }} \\
\text { Ethanol }\end{array}$ \\
\hline Argentina & $-2 / 3$ & $98 / 101$ & $-26 /-28$ \\
\hline Australia & $4 / 13$ & $101 / 107$ & $-26 /-27$ \\
\hline Chile & $2 / 6$ & $99 / 102$ & $-26 /-28$ \\
\hline China & $-3 / 3$ & $99 / 102$ & $-25 /-28$ \\
\hline California & $2 / 6$ & $101 / 104$ & $-26 /-28$ \\
\hline India & $12 / 15$ & $109 / 111$ & $-23 /-27$ \\
\hline Macedonia & $1 / 6$ & $100 / 104$ & $-26 /-28$ \\
\hline Mexico & $1 / 6$ & $100 / 103$ & $-26 /-27$ \\
\hline New Zealand & $0 / 4$ & $98 / 102$ & $-27 /-29$ \\
\hline South Africa & $3 / 11$ & $103 / 107$ & $-25 /-28$ \\
\hline Tunisia & $4 / 9$ & $104 / 106$ & $-25 /-26$ \\
\hline Turkey & $1 / 6$ & $101 / 105$ & $-24 /-26$ \\
\hline
\end{tabular}


Table 4. Typical variation of stable isotope ratio of water and ethanol in wines from Central and Southern European wine growing zones.

\begin{tabular}{|l|l|l|}
\hline Wine growing zone Europe & \multicolumn{1}{|c|}{$\begin{array}{c}\text { Central } \\
\text { Europe }\end{array}$} & \multicolumn{1}{|c|}{$\begin{array}{c}\text { Southern } \\
\text { Europe }\end{array}$} \\
\hline$\delta^{18} \mathrm{O} \%$ V-SMOW water & -4 to +3 & -1 to +6 \\
\hline$(\mathrm{D} / \mathrm{H})_{\mathrm{I}}$ ppm ethanol & 97 to 103 & 99 to 105 \\
\hline$(\mathrm{D} / \mathrm{H})_{\text {II }}$ ppm ethanol & 121 to 127 & 125 to 132 \\
\hline$\delta^{13} \mathrm{C}[\%$ o $]$ V-PDB ethanol & -30 to -27 & -27 to -24 \\
\hline
\end{tabular}

water, and variables describing the climate and the geography of the production area in Italy. About 4000 wine samples collected over 11 years and all the official isotopic parameters, as well as a large number of significant climatic and geographical descriptors were considered. By use of exploratory visualization tools, regression analysis and linear modelling it was shown, that $\delta^{18} \mathrm{O}$ followed by $(\mathrm{D} / \mathrm{H})_{\mathrm{I}}$ have the strongest relationship with climate and location. The dominant variables were latitude, with a negative relationship and $\delta^{18} \mathrm{O}$ and $\delta^{2} \mathrm{H}$ of precipitation and temperature, both with positive relationships. The results are a clear example that multivariate correlations and models help to describe relations between isotopic patterns and meta-data of wines.

\subsection{Cut-off values}

The term "cut-off value" may be used to define a interval of stable isotope ratios outside the confidence interval of the normal distribution of a data set of reference samples. However the term can also be used to define limits grapes naturally are incapable to exceed. Such cut-off values are important with regard to wines for which almost no information on geographic origin or vintage is available. With cut-off values a few isolated cases of almost artificial wine products were detected by wine control bodies in the EU during the last years.

The cut-off values of water and ethanol beyond the natural range (cf. Table 5) are derived from long-term observations for otherwise inconspicuous wines.

Nevertheless, in case of the use of cut-off values for authentication or proof of adulteration, it is imperative to consider potential parameters which might be responsible for an extreme stable isotope ratio. Thus by severe water deficit the $\delta^{13} \mathrm{C}$-value of wine ethanol may approximate values of $-22 \%$ V-PDB $[14,36]$. The $\delta^{18} \mathrm{O}$-value of water of wines from grapes harvested very late or even in frozen state (e.g. ice-wine) my decline even below $-5 \%$ o V-SMOW [37].

Table 5. Cut off-value range of stable isotope ratio of wine water and ethanol.

\begin{tabular}{|c|c|}
\hline Isotope ratio & Cut-off value range \\
\hline$\delta^{18} \mathrm{O} \% \circ$ V-SMOW (Water) & $<-5$ \\
\hline$(\mathrm{D} / \mathrm{H})_{\mathrm{I}} \mathrm{ppm}($ Ethanol) & $<96$ \\
\hline$\delta^{13} \mathrm{C} \%$ V-PDB (Ethanol) & $>-22$ \\
\hline
\end{tabular}

\section{Cases of frauds and adulteration}

25 years history of authentication of wine using SIRA is not only a history of collecting, analyzing, and evaluating stable isotope data of authentic wines in data banks, but also a history of the detection of illegal manipulations, adulterations, and mislabeling. In every year the official German control bodies which use SIRA reveal fraud cases of wines. Manipulations like non-authorized chaptalization, water addition, or sweetening with beet sugar, cane sugar, or mixtures of such sugars were detected almost every year. Mislabeling of geographic origin however could be proved only in a few cases. In single years of the 25 years period also large scale adulterations of wines from one origin or country, so-called "wine scandals", became publicly known. In the following some typical cases of illegal or minor manipulations and the way of their detection are shortly presented.

Figure 5 shows the example of the proof of chaptalization of a wine by monovariate evaluation of the $(\mathrm{D} / \mathrm{H})_{\mathrm{I}}$ ratio of ethanol.

The issue was to prove, whether the $(\mathrm{D} / \mathrm{H})_{\mathrm{I}}$ ratio of $98.4 \mathrm{ppm}$ (tagged sample) indicates a chaptalization. On the basis of the significance interval of the Student$t$-distribution it was verified, that the suspicious value of $98.4 \mathrm{ppm}$ is outside the distribution of the EU-WineDB, (i.e. beyond the calculated minimum value of $98.9 \mathrm{ppm}$ ( $p=95 \%$ ) for non-chaptalized wines) and therefore chaptalized [13].

Figure 6 shows the bivariate proof of an adulteration of a wine from a non-EU country. The reference data was a set of otherwise unsuspicious wines from the same country and the same vintage. The bivariate plot of the $\mathrm{d}^{18} \mathrm{O}$-values of water and $\delta^{13} \mathrm{C}$-value of the ethanol of the referencesamples show the outlying character of the suspect sample. The $\delta^{13} \mathrm{C}$-value of ethanol (-24\%o V-PDB) of the suspicious sample indicates a chaptalization with cane sugar whereas the $\delta^{18} \mathrm{O}$-values of water $(-0.26 \%$ V-SMOW) was a siginificant proof of an addition of water.

Figure 7 shows a bivariate plot of $\delta^{18} \mathrm{O}$-values of water and the $(\mathrm{D} / \mathrm{H})_{\mathrm{I}}$-ratio of ethanol of commercial wine samples without denominations but originating all from one country. For some of the wines even no information on vintage was available. By comparison with data from

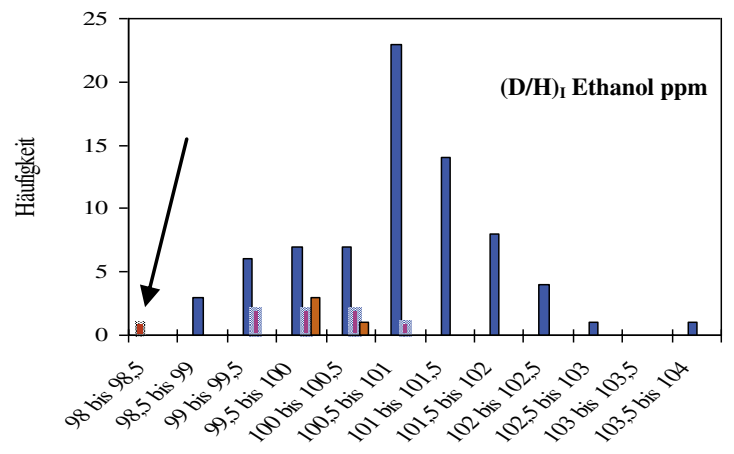

Figure 5. Monovariate proof of chaptalization of a wine by distribution and confidence interval of the $(\mathrm{D} / \mathrm{H})_{\mathrm{I}}$-value of ethanol of reference samples [13]. 


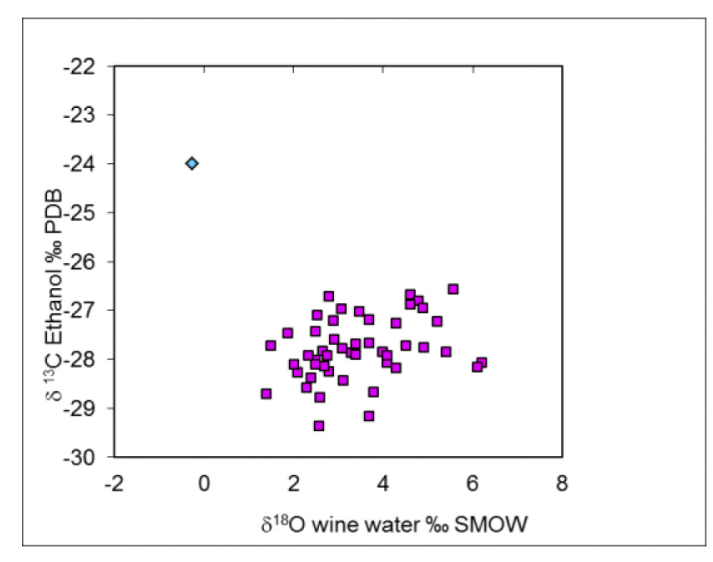

Figure 6. Proof of adulteration of a wine by chaptalization with $\mathrm{C}_{4}$-sugar as well as water addition.

samples of the EU-WineDB it was approved, that the isotope ratios of most samples were authentic or borderline (broken encircled line) for the country considered.

However the encircled samples in Fig. 7 with $\delta^{18} \mathrm{O}-$ values of water less than $<2 \%$ V-SMOW were assessed to be outside the confidence interval as a result of water addition. One product, specified as "grape must" even had a $(\mathrm{D} / \mathrm{H})_{\mathrm{I}}$-value of about $93 \mathrm{ppm}$ which is a typical example of a cut-off value case; in fact the product was not a grape must but an aqueous solution of sucrose from beet sugar.

The proof of geographic origin is the most complex issue of wine authentication. It is important to consider not only stable isotope data but also conventional data and meta-data for interpretation on the basis of stable isotopes. If sufficient sophisticate experience as well as information on meta-data of a wine are available it is possible to make a preliminary validity check on the authenticity of the geographic origin. However a final assessment can only be based on authentic samples as close as possible to origin, year and date of vintage of the sample to be analysed. If possible, authentication should be based not only in monovariate or bivariate but rather on multivariate evaluations.

Wachter [33] showed how to prove the authenticity of a suspect wine, concerning its geographic origin and year of vintage, by calculating the squared Mahalanobis distance $\left(\mathrm{dm}^{2}\right)$. The calculaton of $\mathrm{dm}^{2}$ was based on $(\mathrm{D} / \mathrm{H})_{\mathrm{I}}$, $(\mathrm{D} / \mathrm{H})_{\mathrm{II}}$, and $\delta^{13} \mathrm{C}$ of wine ethanol and $\delta^{18} \mathrm{O}$ of wine water

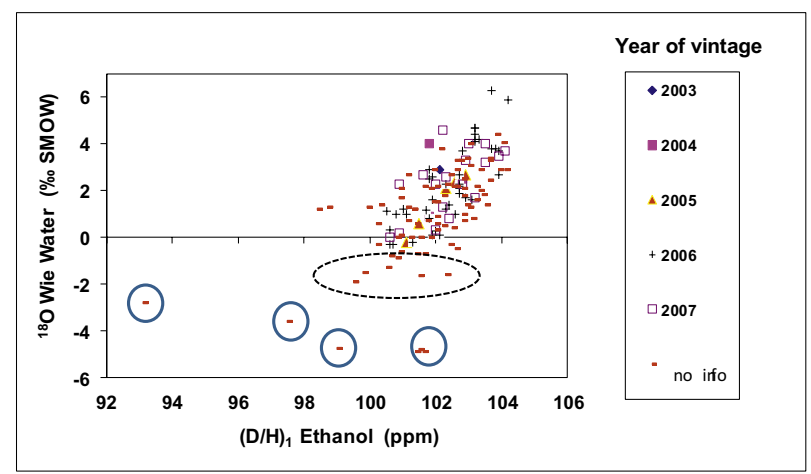

Figure 7. Authentication of wines with incomplete information on details of origin or year of vintage.

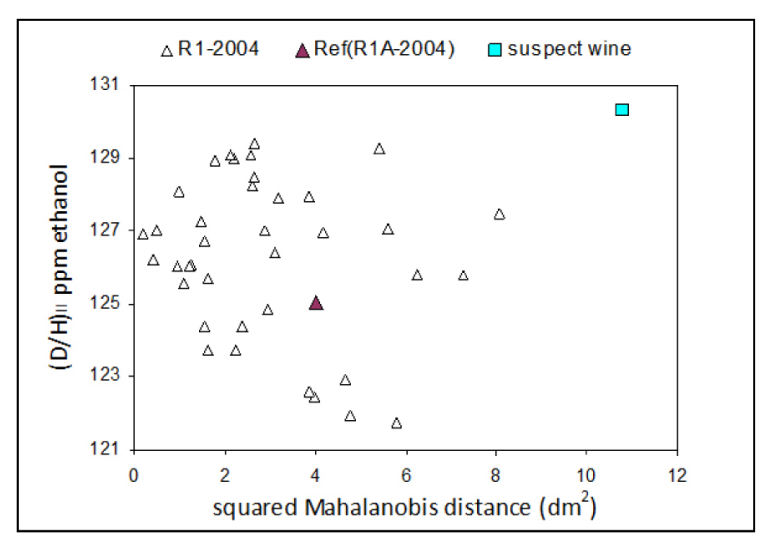

Figure 8. Plot of $(\mathrm{D} / \mathrm{H})_{\mathrm{II}}$ versus Mahalanobis Distance $\left(\mathrm{dm}^{2}\right)$ of a "suspect wine", wines from "reference group R1-2004", and a direct counterpart "Ref (R1A-2004)" of suspect wine; $\mathrm{dm}^{2}$ based on $(\mathrm{D} / \mathrm{H})_{\mathrm{I}},(\mathrm{D} / \mathrm{H})_{\mathrm{II}}$ and $\delta^{18} \mathrm{O}[33]$.

and used as measures of similarity between the isotope patterns of a suspect wine and those of authentic reference wines. Combined with hypothesis testing this multivaraite statistical procedure may allow a more objective conclusion whether the wine is authentic or not with regard to the declared origin. The crucial isotope profiles on which the refusal of authenticity is based can be identified by means of the established tools of discriminant analysis.

In the case of a wine sample with suspicious stable isotope data, corresponding authentic samples from EU wine databank (EU-WineDB) were used as references. The parameter $\mathrm{dm}^{2}$ calculated for $(\mathrm{D} / \mathrm{H})_{\mathrm{I}},(\mathrm{D} / \mathrm{H})_{\mathrm{II}}$, and $\delta^{18} \mathrm{O}$ for the suspect sample finally indicated, that it's stable isotope pattern is not in accordance with the patterns of the reference samples (Fig. 8). Thus the wine was assessed not to be from the labeled geografic origin.

\section{Conclusions and outlook}

Wine frauds are frequently detected by on-site control of vineries or by accompanying documents. However the implementation and routine use of SIRA with data banks of authentic reference samples will have an additional and -above all- a deterrent effect on fraudulent manipulations of wine. Thus "spot-check" authentication of wine with SIRA should be used further on, not only by official control bodies but also within quality control of wine industry. With this in mind, an improved and more effective transnational cooperation with an enhanced data communication and more effective traceability would be desirable.

${ }^{1} \mathrm{H}-$ Nuclear Magnetic Resonance $\left({ }^{1} \mathrm{H}-\mathrm{NMR}\right)$ analysis of wine using selective suppression of water and ethanol signals becomes more and more in use. ${ }^{1} \mathrm{H}$-NMR provides inherently quantitative and highly reproducible information and is therefore a well-adapted technique for both targeted and non-targeted screening. From one single data set it is possible to both quantify targeted compounds and to classify samples into groups [38]. The combination of ${ }^{1} \mathrm{H}-\mathrm{NMR}$ fingerprinting (profiling) with multivariate analysis ("Wine screener") has already shown promising results for grape variety verification or other specific issues 
of authentication like geographic origin $[38,39]$. Even specific adulterations may be detected in future with this technique. In this respect it is reasonable to use both ${ }^{1} \mathrm{H}-\mathrm{NMR}$ and SIRA, e.g. for a cross-validation for specific issues of authentication. A first promising approach by simultaneous chemometric evaluation of data from ${ }^{1} \mathrm{H}-\mathrm{NMR}$ profiling and SIRA was shown by Monakhova [40].

Finally stable isotopes ratios of wine constituents enable not only authentication of a wine but may also be indicative for viticultural conditions. It was verified, that the $\delta^{13} \mathrm{C}$-value of must sugar or wine ethanol is related to the vine water status and therefore may characterize vineyards for their soil structural capacity to provide water to grapevines or indicates water stress $[14,36]$. Thus $\delta^{13} \mathrm{C}$-values of grape sugar may be utilized for vineyard management purposes [36] or specification and mapping of particular suited vineyards producing wines of very high quality.

\section{References}

[1] M.M. Bender, Phytochemistry 10, 1239 (1971)

[2] J. Bricout, J., AOAC Int. 56, 739 (1973b)

[3] G.J. Martin, M.L. Martin, F. Mabon, M.J. Michon, Anal. Chem. 54, 2380 (1982)

[4] EC-Regulation 2676/1990, Off. J. Eur. Commun. L 272, 64 (1990)

[5] J. Dunbar, Z Lebensm Unters Forsch 174, 355 (1982)

[6] H. Craig, Science 133, 1702 (1961)

[7] H.L. Schmidt, Naturwissenschaften 90, 537 (2003)

[8] G.J. Martin, M.L. Martin, Tetrahedron Letters 22, 3525 (1981)

[9] OIV Compendium of International Methods of Analysis of Wines and Musts, http: / / www . oiv . int / (2014)

[10] FIT-PTS http://www.eptis.org/pts3123 (2011)

[11] Regulation EC No. 555/2008, Off. J. Eur. Commun. L170, 1 (2008)

[12] Regulation (EU) No. 1308/2013 Off. J. Eur. Commun. L 347, 671 (2013)

[13] N. Christoph, A. Rossmann, S. Voerkelius, Mitteilungen Klosterneuburg 53, 23 (2003)

[14] N. Christoph, A. Rossman, C. Schlicht, S. Voerkelius, ACS Book Series 952, 166 (2006)

[15] G.Versini, F. Camin, M. Ramponi, E. Dellacassa, Analytica Chimica Acta 563, 325 (2006)

[16] H. Förstel, J. Huobé, H. Hützen, Z Lebensm Unters Forsch A 204, 103 (1997)

[17] N. Christoph, G. Barátossy, V. Kubanovic, B. Kozina, A. Rossmann, C. Schlicht, S. Voerkelius, Mitt. Klosterneuburg 54, 144 (2004),

[18] A. Hermann, S. Voerkelius, Am. J. Enol. Vitic. 59, 194 (2008)
[19] F. Thomas, E. Jamin, D. Hammond J., AOAC Int. 96, $615(2013)$

[20] M. Perini, F. Camin, Journal of Food Science 78, 839 (2013)

[21] J.M. Moreno Rojas, S. Cosofret, F. Reniero, C. Guillou, F. Serra, Rapid Comm. Mass Spectrometry 21, 2447 (2007)

[22] C. Fauhl, R. Wittkowski, J. Lofthouse, S. Hird, P. Brereton, G. Versini, M. Lees, C. Guillou, J. of AOAC Int. 87, 1179 (2004)

[23] F. Serra, F. Reniero, C. Guillou, J.M. Moreno, J. M. Marinas, F. Vanhaecke, Rapid Commun Mass Spectrom. 19, 1227 (2005)

[24] A. Hermann, Z. Lebensm Unters Forsch. A. 208, 194-197 (1999)

[25] G. Calderone, N. Naulet, C. Guillou, F. Reniero, J. Agric. Food Chem, 52, 5902 (2004)

[26] M. Boner, H. Förstel, Office International de la Vigne et du Vin. Paris. F.V. 1152. (2001)

[27] L. Martinelli, M.Z. Moreira, J. Ometto, A. R. Alcarde, L. A. Rizzon, E. Stange, J. R. Ehleringer, J. Agric. Food Chem., 51, 2625 (2003)

[28] I. González-Martin, C. González-Pérez, E. MarquésMacías, J. Agric. Food Chem. 45, 1149-1151 (1997).

[29] T. Bigwood, M. Sharman, A. Aldus, M.J. Dennis, J. Wine Res. 9, 155 (1998)

[30] A. Rossmann F. Reniero, I.Moussa, H.L. Schmidt G. Versini, M.H. Merle, Z Lebensm Unters Forsch A. 208, 400 (1999)

[31] A. Hermann, Mitt. Klosterneuburg, 53, 132 (2003)

[32] J.E. Gimenez-Miralles, D.M. Salazar, I. Solana, J. Agric. Food Chem. 47, 2645, (1999)

[33] H. Wachter, N. Christoph, S. Seifert, Mitt. Klosterneuburg 59, 237 (2009).

[34] N. Dordevica, R. Wehrensa, G.J. Postma, L.M.C. Buydens, F. Camin, Analytica Chimica Acta 757, 19-25 (2012)

[35] F. Camin,.N. Dordevic, R. Wehrens, M. Neteler, L. Delucchi, G. Postma, L. Buydens, Analytica Chimica Acta 853, 384-390 (2015)

[36] C. van Leuwen, O. Tregoat, X. Chone, B. Bois, D. Pernet, J.P. Gaudillère, J. Int. Sci. Vigne Vin 43, 121 (2009)

[37] A. Hermann, Am. J. Enol. Vitic. 65, 4 (2014)

[38] Y. B. Monakhova, T. Kuballa, D. W. Lachenmeier, J. of Anal. Chem. 68, 755 (2013)

[39] R. Godelmann, F. Fang, E. Humpfer, B. Schütz, M. Bansbach, H. Schäfer, M. Spraul, J. Agric. Food Chem. 61, 5610 (2013)

[40] Y.B. Monakhova, R. Godelmann, A. Hermann, T. Kuballa, C. Cannet, H. Schäfer, M. Spraul, D.N. Rutledge, Analytica Chimica Acta 833, 29 (2014) 